\title{
A criança e o desenvolvimento infantil na perspectiva de mães usuárias do Serviço Público de Saúde
}

\section{The child and its development according to the view of mothers who are Public Health Service users}

\author{
Michelli Moroni RABUSKE \\ Débora Silva de OLIVEIRA² \\ Dorian Mônica ARPINI ${ }^{3}$
}

\begin{abstract}
Resumo
O presente estudo investigou as concepções das mães em relação a criança e em relação ao desenvolvimento infantil, objetivando identificar sua perspectiva acerca das implicações das relações pais-filhos nesse período do desenvolvimento e caracterizar as explicações atribuídas por elas aos comportamentos dos filhos. Participaram do estudo mães usuárias da rede pública de saúde, com as quais se realizaram entrevistas examinadas através de análise de conteúdo. Observou-se que as mães evidenciaram diferenças entre a infância de hoje e de "antigamente", sendo essa um período de aprendizagem e vulnerabilidade. Os comportamentos dos filhos foram avaliados como típicos e atípicos, a partir de parâmetros como idade, gênero e comparação com outras crianças. As mães atribuíram importância ao estabelecimento dos vínculos mãe-filhos e às necessidades físicas, emocionais e relacionais durante o desenvolvimento infantil. Constatou-se que a construção da imagem da infância e da criança esteve permeada tanto pelas vivências cotidianas, de cuidado, educação e convívio familiar, quanto pelo saber científico,
\end{abstract}

Palavras-chave: concepções de infância; crianças; desenvolvimento infantil; infância; mães; relações mãe e filho.

\begin{abstract}
The present study has investigated mothers' view about their own child and its development. This project purpose was to identify their perception about parents-children relationship influences to the development, and their children behaviors comprehension. Mothers who were a Public Health Service user have participated of this study. They have been interviewed and the analysis of content had composed the data of this study. According to this procedure it was possible to observe that, for these mothers there are many differences between the childhood from nowadays and their childhood, and in their opinion, this period is a learning and development period. The children behaviors were evaluated as typical and atypical considering parameters such as: age, gender, and comparison to other children. These mothers had emphasized the mother-children ties as a physical and emotional support to the infant development. They also consider the childhood and the child images a structure composed by the quotidian experiences, care, education and familiar interfaces, and also by scientific knowledge.
\end{abstract}

key words: childhood conceptions; children; childhood development; childhood; mothers; mother child relations.

\section{Q V V V}

1 Doutoranda, Programa de Pós-Graduação em Psicologia, Centro de Filosofia e Ciências Humanas, Universidade Federal de Santa Catarina. Campus Universitário, 88040-500, Trindade, Florianópolis, SC, Brasil. Correspondência para/Correspondence to: M.M. RABUSKE. E-mail: $<$ michelli_rabuske@yahoo.com.br>.

2 Mestranda, Programa de Pós-Graduação em Psicologia do Desenvolvimento, Universidade Federal do Rio Grande do Sul. Porto Alegre, RS, Brasil.

3 Departamento de Psicologia, Universidade Federal de Santa Maria. Santa Maria, RS, Brasil.

Agradecimentos: ao Centro Materno-Infantil, Santa Maria, RS, pela autorização para a realização da coleta de dados da pesquisa. 
O reconhecimento da infância como uma fase diferenciada do ciclo de vida é relativamente recente na história da humanidade (Santos, 1996). De acordo com Tomás (2001), os historiadores da infância localizam na época pós-medieval o registro de mudanças sociais, políticas e econômicas que serviram de base para a concepção moderna de infância, entendida como esfera da vida social específica e separada da esfera dos adultos.

Considera-se a infância como categoria histórica contextualizada cultural e socialmente, de modo que se encontram diferentes imagens sociais da infância ao longo da história. O conjunto de significações, símbolos e valores atribuídos à infância diferem de sociedade para sociedade, de época para época, conforme refere (Lajolo, 1999, p.226):

Muito embora os seres humanos tenham sempre sido frágeis, pequeninos e leves e - quando sobrevivem...- tenham sempre ganhado altura e peso ao longo de muitos anos até que ficam fortes e seu tamanho se estabiliza, e seja sua idade contada por anos, por luas, ou por chuvas, o significado de ser um ser humano deste ou daquele tamanho, com muita ou com pouca altura, varia enormemente de um lugar para o outro, de um tempo para outro.

Atribuir "um sentido de construção histórica à infância implica analisar como as práticas socioculturais (sejam elas os discursos, as ações e as instituições) possibilitam, circunscrevem e determinam certos tipos de experiência durante a infância" (Castro, 1996, p.308). Essa abordagem compreende as transformações das práticas socioculturais e dos costumes, os quais marcaram as representações da infância e da criança e envolveram, nos séculos XVIII e XIX, o surgimento da ética capitalista e de novos interesses econômicos, do sistema educacional formal, da racionalidade científica, bem como a emergência de novos métodos de criação dos filhos e mudanças na estrutura e no quadro psicológico e emocional da família (Ariès, 1981).

Assim, o tratamento diferenciado destinado à infância surge entre os séculos XVI e XVIII, sendo que até esse período a educação das crianças confundia-se com sua inserção nas atividades da comunidade, nos espaços públicos, sendo elas consideradas adultos em miniatura. Com a Revolução Industrial e a conseqüente urbanização, iniciou-se o processo de nuclerização da família extensa do período feudal. Emergiram os sentimentos de intimidade, discrição e isolamento, e a família nuclear moderna incorporou uma função afetiva, e a saúde e a educação das crianças passaram a ser valores centrais (Ariès, 1981; Tomás, 2001; Chaves, Cabral, Ramos, Lordelo \& Mascarenhas, 2002).

No Brasil, a vinda da corte portuguesa foi acompanhada pelo aparecimento do movimento higienista, o que, de acordo com Costa (1983), produziu importantes modificações na vida familiar. Alves (1999, p.233) afirma que "ao lado do marido machista e autoritário cria-se a figura da mulher higiênica e disciplinadora dos filhos; a criança, revestida de importância econômica e política, passa a ocupar uma posição central na família, cultivando-se o amor entre pais e filhos". Alves afirma que, no século XX, com o desenvolvimento tecnológico e a mobilidade geográfica, o discurso científico médico-psicológico tornou-se o referencial para as práticas destinadas ao cuidado infantil e passou a orientar a relação pais-filhos.

Almeida e Cunha (2003) também se referem à ênfase atribuída, no século XX, às responsabilidades e ao papel do adulto em relação à criança a partir da institucionalização da Declaração Internacional dos Direitos da Criança, em 1959. Os cuidados dirigidos à infância deixaram de ser apenas manifestações afetivas espontâneas e arbitrárias, e se tornaram uma regra social. Tais comportamentos e atitudes socialmente construídos adquiriram um caráter de lei, como pode ser observado com a instauração do Estatuto da Criança e do Adolescente, no Brasil, em 1990.

Os conceitos e teorias do desenvolvimento humano das diferentes especialidades científicas também contribuem, portanto, para a construção social da infância. Segundo Castro (1996), a infância tornou-se, atualmente, o objeto do cuidado e dos discursos de um número crescente de especialistas - médicos, pedagogos, psicólogos, sociólogos, fonoaudiólogos, entre outros - fazendo com que uma multiplicidade de representações e imagens sobre a infância seja possível. O desenvolvimento humano, para Brayner (2001), não está fundado somente no crescimento psicológico e cognitivo, mas também nos modos específicos de acesso à informação social - mídia e divulgação científica, por exemplo - os quais contribuem para a construção das imagens sobre a infância. 
Estudos apontam mudanças no que se refere à imagem da criança, às relações pais-filhos e aos padrões educacionais da família brasileira ao longo do século XX (Bonin, 1987; Bastos, 1991; Alves, Caldana \& Silva, 1997; Benincá \& Gomes, 1998). As crianças de hoje são consideradas mais vivas, sagazes e participativas (Bonin, 1987). As transformações são atribuídas aos meios de comunicação e às mudanças na relação pais-filhos no que tange principalmente ao aspecto da autoridade (Benincá \& Gomes, 1998). Alves et al. (1997) localizam em meados da década de 1970 o fenômeno da incerteza e insegurança dos pais quanto à melhor maneira de educar os filhos, em relação ao futuro e às conseqüências negativas de suas práticas de cuidado e educação.

Para Graminha e Martins (1994) e Boarini e Borges (1998), as dúvidas enfrentadas pelos pais na educação dos filhos são um dos fatores que motivam a procura por atendimento infantil nos serviços públicos de saúde mental. Essas autoras afirmam que a clientela infantil tem constituído maioria em comparação aos adultos, o que sinaliza para uma demanda dos próprios adultos - familiares, professores e demais profissionais - por geralmente atribuírem o problema às crianças. De acordo com Moura e Gabassi (1998), uma das queixas mais freqüentes entre os encaminhamentos para tratamento psicológico é a"imaturidade"da criança. O comportamento das crianças foi avaliado pelos pais como inapropriado para a idade por apresentarem acentuada dependência na realização de tarefas de autocuidado comuns na vida diária.

A literatura apresenta a preocupação de pesquisadores em reconhecer crenças, valores dos pais (Reppold, Pacheco, Bardagi \& Hutz, 2002) e sua compreensão sobre o desenvolvimento infantil (Frank \& Rowe, 1986; Glascoe, MacLean \& Stone, 1991), uma vez que embasam a relação pais-filhos e a educação das crianças. O processo de desenvolvimento infantil não ocorre da mesma forma para crianças submetidas a contextos socioeconômicos e culturais distintos, pois é influenciado pelas condições materiais, pelas características subjetivas e pela disponibilidade afetiva dos adultos cuidadores (Bastos, 1991; Oliveira \& Alvarenga, 1993; Rothbaum, Pott, Azuma, Miyake \&Weisz, 2000). Além disso, Glascoe e Dworkin (1995), Glascoe (1997; 2000) e Figueiras, Puccini, Silva e Pedromônico (2003) apontam que os profissionais que atuam na área da saúde da criança devem considerar atentamente a importância do papel dos pais na detecção precoce de problemas emocionais, comportamentais e físicos em seus filhos.

Nesse sentido, conhecer as concepções de infância desses adultos, seus sistemas de crenças e valores torna-se relevante já que as crenças sociais sobre o desenvolvimento têm implicações para o processo desenvolvimental efetivo dos sujeitos (Almeida \& Cunha, 2003), para a socialização das crianças (Bonamigo \& Rasche, 1988; Alves, 1999), para a relação entre adultos e crianças e para as práticas de cuidado a elas destinadas (Lordelo, Fonseca \& Araújo, 2000). A presente pesquisa tem como objetivo investigar as concepções de mães de crianças até doze anos sobre a criança e o desenvolvimento infantil, buscando identificar suas perspectivas sobre as implicações da relação pais-filhos para a criança, e caracterizar os significados atribuídos por elas aos comportamentos que consideraram típicos e atípicos na infância.

\section{Método}

O local de realização da pesquisa foi o Centro-Materno Infantil, na cidade de Santa Maria, RS. A instituição é referência municipal no atendimento ambulatorial pediátrico e ginecológico pelo Sistema Único de Saúde. Participaram da pesquisa oito mães de crianças até doze anos de idade, as quais buscaram atendimento pediátrico para os filhos no referido local entre os meses de junho e setembro de 2002. As mães foram abordadas quanto à sua disponibilidade em participar enquanto aguardavam a consulta na sala de espera.

As participantes tinham entre 17 e 33 anos de idade, ensino fundamental incompleto, renda familiar em torno de 1,5 salário mínimo.

Dentre as oito mães participantes, cinco tinham dois filhos, duas tinham um filho e uma tinha quatro filhos. Os relatos das entrevistadas referiram-se a 16 crianças, que podem ser caracterizadas em relação à faixa etária e ao sexo, com os nomes fictícios das mães, da seguinte maneira: filhos de zero a 3 anos (menina - Elisa e Maria; menino - Ana, Luisa, Nara, Paula e Rosa), filhos de 4 a 6 anos (menina - Júlia, Luisa, Maria, Nara, Rosa; menino - Maria ), filhos de 7 a 12 anos (menina - Júlia; menino - Elisa). 
No que se refere às relações familiares, apenas uma das participantes não mantinha relação conjugal, sendo que para cinco delas o companheiro era o pai biológico de todos os filhos. Para duas, o companheiro era o pai biológico do filho mais novo e desempenhava a função paterna também para os demais.

Nesta pesquisa, de caráter transversal e exploratório, utilizou-se a técnica de entrevistas individuais semi-estruturadas, gravadas e transcritas na íntegra, para registro e posterior análise dos dados. As entrevistas tiveram, aproximadamente, 30 minutos de duração. A análise qualitativa foi realizada de acordo com a metodologia de análise de conteúdo temática categorial proposta por Bardin (1977), sendo as categorias definidas a partir do conteúdo encontrado nas entrevistas, ou seja, a posteriori. Os resultados serão ilustrados por trechos das falas das entrevistadas, acompanhados pelos nomes fictícios.

\section{Resultados}

As concepções maternas sobre a criança e o desenvolvimento infantil foram apreendidas a partir de cinco categorias:

1) Representação da criança associada à percepção sobre os próprios filhos: as mães utilizaram a vivência com seus filhos como referência para caracterizar o que é a criança. Os termos mencionados foram: "arteiro","tinhoso," "teimoso," "esperto", "inteligente".

É arteiro porque mexe em tudo, não dá pra deixar nada... (Paula).

Ele é muito esperto, se ele vê a gente falando de uma coisa e ele grava aquilo ali ..., tudo ele quer olhar, tudo ele quer saber, tudo ele pergunta ... (Ana).

A esperteza e a inteligência foram características avaliadas positivamente pelas mães, pois foram consideradas como evidências surpreendentes da capacidade das crianças para a compreensão do mundo. As mães definiram a inteligência a partir das competências apresentadas pelos filhos nas situações informais, tais como: participação ativa nas tarefas cotidianas relativas à higiene pessoal e ao autocuidado, capacidade de observar o que ocorre ao seu redor, prestar atenção e questionar.
E eu falava e ele me atendia, me obedecia, não era difícil não, no tamanho dele. Já ela é mais teimosa, ela já é mais inteligente que ele, mais arteira. Porque ela não é, não é assim, ... gosta de aprender, ... tudo ela qué fazê sozinha, ela não sabe, a gente vai ensiná e ela não aceita, ela qué descobri da maneira dela (Elisa).

... ele é bem interessado, qualquer coisa que a gente quer fazer, ele quer ajudar, sabe ... eu acho ele inteligente. ... como eu vou dizer, ele está sempre atento, então o que ele vê que a gente faz, ele quer fazer, sabe? (Paula).

A desobediência e a mentira foram relacionadas às dúvidas sobre a capacidade de as crianças agirem intencionalmente. As mães afirmaram ter dificuldades em confiar no que os filhos dizem. Esses comportamentos foram apontados como freqüentes pelas mães de crianças de até quatro anos de idade.

... ele não fala, ou às vezes ele é muito mentiroso também. ... não dá muito pra acreditar nele... pergunto e ele fala mentira.... Até assim pra não ter que vir no médico, que ele sabe, tá ressabiado de tomar injeção já, aí ele mente que não tem nada... (Ana).

... por exemplo quando a gente fala pra ela, dá conselho pra ela não ser teimosa, ter modos, ela escuta mas dali a pouco ela tá fazendo a mesma coisa de novo, ela diz que ela esquece, e por isso que ela volta a fazer, eu não sei se é uma maneira dela se, como é que eu vou dizer, se defender do que a gente pergunta pra ela... (Luisa).

2) A criança de hoje comparada à de "antigamente": as mães consideraram que educar as crianças hoje é diferente de educar na época em que elas eram crianças. Também mencionaram quea relação com os filhos está marcada por essas diferenças, pois a criança de hoje foi apresentada como menos submissa ao adulto. Os significados relacionados a tal diferença, por vezes contraditórios, foram "falta de educação/desobediência" e "autonomia/inteligência". O desenvolvimento da autonomia na infância foi considerado como um processo natural e independente da participação dos adultos. O termo de comparação foi a criança de hoje versus a criança de antigamente, em referência à sua própria infância e à educação recebida de seus pais. 
Até essas coisas de educação, de tratar os mais velhos, as crianças hoje não têm educação, chegam e dizem "oi vó, como tu tá?", eu acho feio isso, perde o respeito (Rosa).

... bah, é bem diferente, porque a minha geração, a gente falava uma vez só, e a gente já entendia, a gente respeitava quando saia na casa dos outros, hoje em dia, a gente tem que tá chamando 3, 4, 5 vezes e a gente explica, explica e parece que não entra na cabeça, ah meu Deus, é bem diferente (Elisa).

3) A infância como período de vulnerabilidade e aprendizagem: a criança foi considerada pelas mães como "influenciável," "vulnerável"ao exemplo na medida em que teria uma "tendência" a observar e imitar comportamentos de outras crianças e adultos. Isso indica a compreensão de que o desenvolvimento infantil é influenciado pelas experiências relacionais.

Ele quer fazer as mesmas coisas que eles [tios de 18 anos], se eles disserem uma coisa aí ele pega e diz também. Então tem essa influência né (Ana).

Eu acho que é a gente que ensina ela né, porque a neta da mãe, de 11 anos é tinhosa, ensina, daí ela aprende né, criança é criança, ... de certo ela vê as outras crianças fazendo, e aprende né, ela vêas outras crianças falarem né... (Maria).

Dentre as influências apontadas pelas mães, o exemplo dos pais e dos demais adultos foram considerados centrais na aprendizagem dos comportamentos relativos aos estereótipos de gênero. Esses estereótipos estiveram associados aos modelos socioculturais de que o menino precisa de exemplos paternos e não deve aprender a fazer"coisa de mulher" com a mãe.

Isso aí é o que eu digo sempre lá, que ele vivendo só comigo em casa, o que eu tiver fazendo, que é serviço de mulher, ele vai querer fazer também, né, então o que eu digo pro pai dele sempre, que ele tem que ficar mais tempo com ele, ... porque ele é gurizinho, e ele tem que aprender coisa de guri, né, não tem que aprender coisa de mulher, que a mulher faz em casa, tipo lavar uma louça, ou qualquer outra coisa assim, varrer uma casa, quando ele era menor ele vivia com a vassoura na mão querendo varrer a casa... (Ana).

A infância foi, portanto, definida como período de aprendizagem. A criança precisa receber orientação sobre o que é "certo e errado", sendo essa uma responsabilidade dos adultos.

Eu acho que tem que ir falando pra ele, "assim sim, assim não". Tem que ir dizendo pra ele o que é certo e o que não é, o que não pode fazer, sozinho ele não vai aprender ... (Rosa).

... a gente dá exemplo, a vó dele fala também, o exemplo que eu digo assim, olha, de não ser uma criança rebelde, de não ser uma criança mal educada, que fale nome ... (Ana).

Os discursos indicaram uma preocupação das mães quanto a serem elas quem deve ensinar a criança e, principalmente, incentivar que os filhos as respeitem. Acreditam que se perderem o controle sobre os filhos, eles podem "tomar conta" da situação.

... ela embrabece, dá na gente, ... mas querê dá na gente que é mãe né, eu só cuido deles né, pra depois dále pau na gente né, tem que educar eles primeiro né, pra depois, um dia quando são grande vão fazê o que querem da gente né. ... criança não dá pra deixá né, depois cresce né, faz coisa horrível! (Nara).

Mas é difícil, eu não ponho de castigo, e tá dando neles assim, de dá, é difícil, mas mais eu falo, falá eu falo, até acho que eu falo demais (risos) é, eu acho que deveria colocar mais de castigo, eu acho que resolveria mais... eu acho até que ele já tomou conta né... (Elisa)

4) Desenvolvimento infantil: o desenvolvimento infantil foi considerado pelas mães como um período em que a presença, a atenção e o carinho da mãe são fundamentais. Observou-se a referência de mães que decidiram parar de trabalhar, geralmente durante o primeiro ano após o nascimento da criança, para permanecerem em casa exercendo as atividades de cuidado após o período de licença maternidade. A saúde dos bebês durante o primeiro ano de vida foi estreitamente relacionada ao cuidado materno.

... vou ficar em casa, eu acho muito pequenininho pra deixar assim, pra sair e deixar em creche, sei lá, às vezes, nunca é assim, a mãe, ... eu acho que se deixo ele com alguém assim vai estranhar ou pode ficar doente, e aí é melhor ... (Luisa).

As mães diferenciaram cuidado biológico e cuidado afetivo, e enfatizaram que oferecer apenas as condições materiais não é suficiente para que as 
crianças se desenvolvam adequadamente. Elas consideraram ter dificuldades em suprir as necessidades afetivas dos filhos, sendo que avaliaram estar desempenhando mais adequadamente os cuidados biológicos. Isso indica que elas percebem a importância do carinho e do estabelecimento do vínculo mãe-filho no processo de desenvolvimento infantil.

É que a gente por mais que tu tem vontade, dá carinho para um, tu dá carinho, né, assim. Às vezes, é muita criança e tu não consegue dá aquele carinho, né... (Maria)

Ou talvez até eu fico pensando que é um pouco de carinho que falta né, porque já tá longe do pai e pelo menos da mãe. Porque eu já não sou muito de tá dando, sabe, de tá agarrando. Gosto deles e tudo, mas não sou de tá dando carinho, sempre tem as mães, sempre dão. ... Eu gosto deles, na hora, que tiver doença eu me preocupo com eles, não saio, se tiver que sair eu saio, eles ficam com uma pessoa de família, jamais deixei eles atirados, sou bem assim, só que não sô de tá pegando, de tá dando carinho, passá a mão no rosto, dar beijo, aquela coisa toda. ... às vezes, eu penso que falta um pouco de carinho da minha parte, talvez (Elisa).

5) Parâmetros para a atribuição de sentido aos comportamentos, considerados pelas mães como típicos e atípicos: na avaliação do comportamento de seus filhos como típico ou atípico, as mães fizeram uso de comparações entre eles e outras crianças com as quais se relacionam.

Ela é assim meia possessiva até ... porque eu acho que um pouco é por isso, ela se criou até há pouco tempo sozinha assim, não tinha aquela outra criança pra dividir as coisas com ela, então eu acho que é, porque geralmente tu pode notar que tudo quanto é criança que se cria sozinha é assim, é possessiva, não gosta de emprestar os brinquedos, eu já andei notando, várias crianças são assim (Luisa).

A idade foi outro parâmetro para a avaliação dos comportamentos e da "capacidade de entendimento" da criança. As mães consideraram tal parâmetro como um fator relevante para que a criança compreenda o que o adulto Ihe explica ou ensina. Assim, elas avaliaram o desenvolvimento cognitivo como um processo que se torna gradualmente mais complexo durante a infância.
... que nessa idade eles tem que andar dentro de casa né, e não incomodando na casa dos outros né, ela não entende né, agora tá entendendo né, com 3, 4 anos ela tá entendendo.... eu acho que a partir dos 6 anos, que daí eles já tão grande daí né ... eu acho que eles na idade dela não entendem né? Sabem pouco ainda né.... eu acho que só com 6 anos pra ela entendê bastante coisa, assim, tem alguma coisa que ela entende já, mas tem algumas coisas que eles não entendem (Nara).

Eu acho que até os três (mexer em tudo) ... porque tinha uma guriazinha que eu cuidava também, até os 4 anos ela era assim, sabe arteirinha, sapeca, mexia em tudo, e nos 4 foi se acalmando, já era mais quietinha. E entendia mais bem as coisas que a gente diz. Então até os 3 e 4 anos eu acho que a criança faz (Paula).

O comportamento das crianças foi considerado típico e atípico a partir do gênero. As definições das características para a feminilidade e a masculinidade foram delimitadas de forma rígida. As meninas se comportam de forma"calma", são "quietas" e cuidam da aparência, enquanto os meninos são "agitados", "agressivos" e "arteiros".

... A minha mãe que sempre diz, criança quieta, principalmente, guri, ou tá doentinha, ou tem alguma coisa, pois, geralmente, tudo que é guri, tudo que é criança, faz festa né, é inquieta. ... elas [as meninas] não gostam de se sujar, gostam mais de se cuidar, ficam mais limpas, os guri não (Paula).

Eu acho que o que motiva a agitação dele é porque ele é criança, porque é guri né, diz que todo o guri é arteiro, mexe ali, mexe aqui né. Eu acho que é por causa disso, por que é guri, porque é arteiro, é mexerico. Ela também era assim né, depois foi se aquietando. ... ela também era assim mas ele é bem mais mexerico. ... eu acho que é porque ele é guri, é arteiro, bem medonho... (Nara).

As características subjetivas dos filhos, e as diferenças entre eles, foram atribuídas ao "gênio", no sentido de "puxar por alguém" da família como influência hereditária, e à "personalidade", como designação para o temperamento. Tais características foram consideradas como definidas a priori, ou seja, foram avaliadas como inatas e não influenciáveis pela relação adultos-crianças durante o desenvolvimento infantil.

... ela é um pouco teimosa, birrenta sabe, mas não sei, talvez isso seja de família, não sei, do gênio. ... 
assim, às vezes a gente diz, fulano é brabo, birrento, porque puxou ao pai, ou puxou à mãe ou uma tia. ... à família do pai dela, que Deus me perdoe, não tem o que tirá nem o que botá e tem do meu pai também. O meu temperamento é bem mais calmo, é que nem o guri já puxou mais por mim assim, no caso, calmo, não é tão agitado ... bah, eu já acho que é a diferença entre os filhos, porque pela idade, às vezes eu até falo, digo, quando tinha tal idade não era assim, é pra mim, é porque um é diferente do outro, ela não é filha do mesmo pai né ... (Elisa).

Porque a mais velha é aquela criança assim mais retrancada, mais quieta, mais na dela, e a outra é aquela criança mais amorosa, de expressar mais o sentimento, toda a hora agarrada, grudada. ... ela sempre foi calminha, desde pequenininha, tu deixava ela ali, brincando com os brinquedinhos dela, ela ficava no mundo dela. A outra não, é aquela coisa de sempre estar chamando a atenção, mostrando a presença dela. ... desde que eu tava grávida, a gravidez duma e da outra foi, ela foi se mexer com 5 meses de gestação, enquanto a outra com 2, 2 e meio já tava ... até me disseram, não, esse vai ser um guri. A personalidade de uma e da outra é totalmente diferente, no modo de ser, no modo de falar, é tudo, sabe, assim desde nenezinho, já vem já de, mesma coisa, não é veio até uma certa idade e depois mudou, desde que ela nasceu, nasceu assim. Totalmente diferente uma da outra (Júlia).

A teimosia, o ciúme e as brigas entre irmãos foram definidos como comportamentos típicos na infância, como "coisa de criança". Entretanto, foram avaliados também como comportamentos que trazem dificuldades para o cotidiano da educação infantil.

Teimosia de criança, né. Coisas que ele faz, às vezes, eu chamo dizendo que não é pra fazer aquilo, e ele faz, sabe? Mas isso eu acho que é já da criança, né? (Maria).

Brigam por causa de ciúmes né, um quer o colo da mãe, depois brigam pelo colo do pai. Então só a mãe não pode dar atenção, brigam por causa do colo, se ele quer sentar no colo do pai, ela também quer. ... ciúmes né, ciúmes de criança, de irmão (Nara).

O ciúme foi apontado por todas as mães que tinham mais de um filho como comportamento presente na relação entre eles. O que motiva o ciúme é a "carência", compreendida como a reação da criança à insuficiência de atenção e afeto por parte dos pais.
As mães afirmaram que as crianças demandam "carinho" e contato corporal - beijos, abraços, colo. A convivência com os irmãos, ou a chegada de um novo irmão, acentuaria a"carência", e as mães sentem que precisam "se dividir" para atender todos os filhos.

... fica assim, ela querendo chamar a atenção dela, sabe, daí então chamar a atenção pra ela, daí desviar do nenezinho .... Ela é muito assim, ela tem bastante carinho, né, a gente sempre mimou ela muito, e ela representa ser muito carente, mas ela não é, assim de nós ela sempre teve muito carinho, muito amor, mas ela é meia, acho que um pouco é o ciúmes, ela é muito ciumenta (Luisa).

Não, eu tento, né, dá carinho para todos, eu deixo. Ah, mas tem a C. que diz ah, a mãe não gosta de mim ... sempre quando eu posso, eles ficam no colo ... eu procuro dá carinho para todos. ... eu digo que a mãe gosta de tudo, né, daí ... eles já vem ficam no meu lado, ficam me beijando. É a carência de criança, né? (Maria).

Os comportamentos identificados como atípicos pelas mães foram os que constituem uma exacerbação do que seria "coisa de criança" ou próprio da infância. Assim, quando se acentuam a desobe-diência, a agitação, a agressividade, e as brigas entre irmãos, as mães estabelecem uma relação causal entre tais comportamentos apresentados pelos filhos e algum problema,"problema de nervos", "problema de cabeça".

... ah, é, ela é um pouquinho desobediente. ... é mais agitadinha. Ah, ela teve problema na cabeça. Teve convulsão, né, teve que tomar aquele Gardenal, né, ela tomo um ano, agora já está bem (Maria).

Quando as crianças apresentaram comportamentos considerados pelas mães como extremamente inapropriados em casa e na escola, bem como sintomas emocionais ou orgânicos, elas afirmaram demandar o auxílio de especialistas, como os professores e os profissionais de saúde - médicos e psicólogos. As mães relacionaram o surgimento desses comportamentos e sintomas a situações específicas, tais como: a prisão do pai, a morte de familiares, a separação conjugal e o nascimento de irmãos. Isso evidencia o reconhecimento de que mudanças nas relações da criança com pessoas significativas podem estar vinculadas às dificuldades e aos sintomas apresentados pela criança.

Quando eu me separei do pai dela ela tinha, ia fazer 3 anos, ela ficou bem, como é que eu vou te dizer, 
ela ... eu tive que levar ela pra médico, ... ela procurava os cantinhos e se acrocava assim nos cantinhos e tremia e chorava, chorava, chorava ... e aí eu ia no doutor, levava ela na psicóloga, 2 vezes na semana, a psicóloga conversava com ela, brincava, e aí assim ... (Rosa).

... porque daí até no médico eu levei pra ver que ele era nervoso, sempre chorão, aí eu desconfiava, digo não pode, uma coisa que o Dr. disse que era problema de nervo, que ele ficava nervoso [após a prisão do pai] ... até na escola também, ele tá meio ruim, assim se comportando assim, sabe ... (Elisa).

\section{Discussão}

A partir dos resultados apresentados, constatou-se que os filhos foram a referência central para as mães, de modo que suas concepções sobre a criança e o desenvolvimento infantil estiveram marcadas pelas experiências relacionadas aos cuidados e à educação de seus próprios filhos. Ao se referirem a eles, utilizaram expressões com significados predominantemente positivos. Os adjetivos utilizados pelas mães para a caracterização dos filhos - "arteiro", "tinhoso", "teimoso", "esperto", "inteligente" - marcaram sua surpresa com a capacidade das crianças para compreender o mundo, configurando um modo de valorização da autonomia. No presente estudo, entretanto, o estímulo à autonomia não foi evidenciado como uma tarefa dos adultos, pois o seu desenvolvimento foi considerado progressivo na infância, ocorrendo de forma alheia à intenção e à intervenção do adulto, conforme também foi observado no estudo de Oliveira e Alvarenga (1993).

A educação das crianças hoje foi considerada pelas mães como mais difícil do que na época em que elas próprias foram educadas, sendo utilizada freqüentemente a comparação "criança de hoje"versus "criança de antigamente". A criança de hoje foi representada como menos submissa ao adulto, mas essa característica recebeu diferentes significados, ora falta de educação e desobediência, ora autonomia e inteligência.

Dentre as características e comportamentos considerados pelas mães como típicos na infância, destacaram-se a teimosia, a desobediência, a mentira, o ciúme e as brigas entre irmãos. Embora considerados por elas como "coisa de criança", esses comportamentos foram avaliados como fontes de dificuldades para o cotidiano da educação infantil por suscitarem dúvidas quanto a confiar no que é dito pela criança e quanto à intencionalidade de suas ações, ameaçando a conquista do respeito por parte dos filhos e a manutenção da autoridade parental. Nesse sentido, essas mães atribuíram importância à educação que dão aos filhos, sentindo-se responsáveis pelo aprendizado de noções de certo e errado, limites e convívio social. A percepção das mães sobre tal responsabilidade adquire relevância, pois de acordo com Guzell e Feagans (2004), a percepção dos pais sobre sua capacidade de cuidado e educação dos filhos está relacionada ao significado atribuído aos comportamentos das crianças. Os autores constataram que os pais que se perceberam como menos capazes de cuidar e exercer controle tendiam a atribuir a culpa e a responsabilidade pelos comportamentos que consideraram negativos exclusivamente à criança.

Outro aspecto que se constatou, e que foi evidenciado de forma semelhante no estudo de Bonin (1987), diz respeito à noção de vulnerabilidade das crianças ao exemplo. Essa noção se vincula à responsabilidade dos adultos em educar e ensinar as crianças através de "bons exemplos". Isso evidencia uma representação da infância como período de aprendizagem a partir das interações crianças-adultos. Conforme afirmam Almeida e Cunha (2003), a visão subjacente à infância associa a criança à idéia de imaturidade e incompletude, sendo o desenvolvimento infantil o período de aquisição de novas competências.

A aprendizagem e o exemplo foram considerados eficientes pelas mães no que concerne às regras morais e sociais, bem como aos estereótipos de gênero. Em contrapartida, as características subjetivas foram, em sua maior parte, atribuídas à hereditariedade, ao temperamento e ao "gênio", no sentido de serem consideradas inatas e não passíveis de alteração pela socialização e educação.

O comportamento das crianças foi avaliado pelas mães como adequado e/ou inadequado principalmente a partir de comparações entre os filhos e/ou outras crianças, seja por situações semelhantes, seja pela faixa etária, seja pela vinculação entre comportamento e gênero. Pode-se corroborar com Bonin (1987) em relação à manutenção de estereótipos 
de que as meninas são mais quietas, passivas, e os meninos mais agressivos, ativos. As mães deste estudo demonstraram preocupação em relação ao gênero e às possibilidades de identificação oferecidas às crianças, procurando incentivar o que é considerado culturalmente adequado para meninos e para meninas, conforme foi também observado por Bonamigo e Rasche (1988) e Costa e Antoniazzi (1999).

A compreensão das mães acerca do desenvolvimento cognitivo dos filhos referiu-se à relação entre faixa etária e "capacidade de entendimento", o que implica a percepção do desenvolvimento gradual dessa capacidade durante a infância. Não houve consenso em relação ao momento em que as crianças começam a ter entendimento de seus atos e compreensão sobre o que os adultos Ihes explicam.

Ao sentimento de "carência", que as mães referiram perceber em seus filhos, foram atribuídos os sentidos de falta de atenção, afeto e contato corporal. Isso evidencia uma preocupação dessas mães quanto ao estabelecimento do vínculo mãe-filhos, a dúvida em relação aos cuidados satisfatórios de sua parte, além da compreensão da necessidade por parte da criança de dois tipos de cuidados - biológico e afetivo - e de que apenas o sustento material não é suficiente para seu bem-estar e desenvolvimento. Nesse sentido, Almeida e Cunha (2003) afirmam que a representação social da criança, como objeto de proteção e cuidados, contempla necessidades físicas, afetivas e educacionais.

As mães avaliaram ter certa dificuldade em suprir as necessidades afetivas dos filhos, ao passo que consideraram desempenhar mais adequadamente as tarefas práticas e cotidianas em relação ao cuidado físico e material, o que também foi encontrado nas pesquisas de Bonamigo e Rasche (1988) e Chaves et al. (2002). Pode-se corroborar com Oliveira, Siqueira e Alvarenga (2000) de que as mães demonstraram estar atentas aos aspectos físicos, emocionais e relacionais no desenvolvimento infantil.

É importante salientar que a presença da mãe foi considerada essencial para o adequado desenvolvimento da criança. Trindade, Andrade e Souza (1997) e Chaves et al. (2002) encontraram resultados semelhantes em suas pesquisas com mães. Ainda que estudos apontem uma crescente participação por parte dos pais (Resende \& Alonso, 1995; Trindade, Andrade \& Souza,
1997; Lewis \& Dessen, 1999), a mães participantes da presente pesquisa indicaram a importância do pai em oferecer o exemplo de comportamento referente à masculinidade para os meninos, mas não mencionaram compartilhar com o pai o envolvimento no cuidado dos filhos. As informantes enfatizaram a importância da presença da mãe na família e na criação dos filhos. Seguindo a tendência observada na literatura, as mães e demais mulheres da família, nas classes populares, ainda detêm predominantemente o papel de agente de cuidados de saúde e educação das crianças (Bonamigo \& Rasche,1988; Oliveira \& Alvarenga, 1993; Oliveira \& Bastos, 2000).

O surgimento de dificuldades ou comportamentos considerados inapropriados bem como de sintomas emocionais ou orgânicos nomeados como "problemas de nervos" e "problema de cabeça" foram vinculados principalmente a mudanças nas relações familiares. Isso indica que as mães compreendem a importância dessas relações para o desenvolvimento infantil. A busca pela ajuda de especialistas - professores, pediatras e psicólogos - foi referida pelas mães quando as crianças apresentaram tais dificuldades e sintomas. A sua resolução foi considerada fora de seu alcance e competência, o que evidencia a atribuição de legitimidade ao discurso especializado acerca da infância. De acordo com Oliveira e Bastos (2000), frente a situações adversas e esgotando-se as competências individuais, os indivíduos recorrem a sua rede de apoio social, constituída pelos níveis formal - profissionais - e informal - familiares, vizinhos, entre outros.

\section{Considerações Finais}

Os resultados deste estudo possibilitaram delinear que as vivências cotidianas com os filhos foram a referência central na construção da imagem da criança pelas mães. Em concordância com a literatura, as noções sobre o desenvolvimento infantil, a relação pais-filhos e as características atribuídas à criança estão fortemente permeadas pelo discurso científico (Bonin, 1987; Alves et al., 1997; Oliveira, Siqueira \& Alvarenga, 2000; Almeida \& (unha, 2003).

Como apontam Oliveira e Alvarenga (1993), evidencia-se a incorporação de conceitos científicos 
sobre a criança, suas características, comportamentos, capacidades e necessidades. Na presente pesquisa, pôde-se apontar as seguintes temáticas como evidências da apropriação do discurso científico, por parte das mães: a ênfase na responsabilidade dos adultos - pais e demais familiares - em relação ao cuidado e educação das crianças; a compreensão das experiências relacionais e do vínculo entre adultos e crianças como essenciais para o desenvolvimento infantil, seja para sua promoção e estimulação, seja para o surgimento de dificuldades e sintomas.

Dentre as referências que podem ser apontadas como dificuldades, consideram-se: a percepção sobre o desenvolvimento da autonomia como "natural", aleatória e independente da ação do adulto; a rigidez na avaliação dos comportamentos das crianças como adequados ou não em relação aos estereótipos de gênero; a concepção de que as características subjetivas das crianças são definidas de forma inata e são pouco suscetíveis à influência da socialização e educação, e, por fim, a atribuição de pouca relevância ao papel do pai nos cuidados destinados às crianças.

A realização de grupos de orientação destinados a familiares de crianças na atenção básica, de caráter interdisciplinar, é uma possibilidade de intervenção do psicólogo para auxiliar os adultos na compreensão do desenvolvimento emocional infantil, oferecendo informações e orientações (Frank \& Rowe, 1986; Graminha \& Martins, 1994; Mondardo \& Valentina, 1998; Moura \& Gabassi, 1998), além de possibilitar o conhecimento de condições sociais e psicológicas e suas influências para o desenvolvimento infantil (Mondardo \& Valentina, 1998; Rothbaum et al., 2000). De acordo com Lo Bianco (1981), a compreensão das concepções de infância e do relacionamento entre pais e filhos, relativa e peculiar a cada grupo social, auxilia na construção de propostas mais pertinentes no trabalho em saúde mental.

Conhecer o modo como os pais percebem a infância e a criança e, conseqüentemente, seus filhos, consiste em importante auxílio para profissionais que atuam na área da saúde da criança. Propostas de intervenção destinadas a pais podem ser construídas mais adequadamente levando-se em consideração suas próprias concepções e necessidades. Como refere Calatayud (1991), no que concerne às ações de prevenção e promoção de saúde em Psicologia, as estratégias utilizadas têm sua eficácia vinculada à pertinência da linguagem e das concepções que as embasam em relação aos sistemas de referência da população a que se destinam. De acordo com Oliveira e Bastos (2000), o conhecimento sobre valores, significados e modos particulares de entender a infância e o comportamento das crianças constituem uma perspectiva para redimensionar a distância entre o universo simbólico da família e dos profissionais, e faz parte das condições necessárias para que orientações sobre práticas educativas e estimulação do desenvolvimento sejam incorporadas no cotidiano das famílias.

\section{Referências}

Almeida, A.M.O., \& Cunha, G.G. (2003). Representações Sociais do Desenvolvimento Humano. Psicologia: Reflexão e Crítica, 16 (1), 147-155.

Alves, Z.M.M.B. (1999). Relações familiares. Texto Contexto, 8 (2), 229-241.

Alves, Z.M.M.B., Caldana, R.H.L., \& Silva, M.H.G.F.D. (1997). Práticas de educação da criança: a emergência do saber técnico-científico. Revista Brasileira de Crescimento e Desenvolvimento Humano, 7 (1), 49-62.

Ariès, P. (1981). História social da criança e da família. Rio de Janeiro: LTC.

Bardin, L. (1977). Análise de conteúdo. Lisboa: Edições 70.

Bastos, A.C.S. (1991). Idéias sobre a criação de filhos: uma invenção cultural. Psico, 22 (2), 63-87.

Benincá, C.R.S., \& Gomes, W.B. (1998). Relatos de mães sobre transformações familiares em três gerações. Estudos de Psicologia UFRN, 3 (2), 177-205.

Boarini, M.L., \& Borges, R.F. (1998). Demanda infantil por serviços de saúde mental: sinal de crise. Estudos de Psicologia UFRN, 3 (1), 83-108.

Bonamigo, E.M.R., \& Rasche, V.M.M. (1988). O processo de socialização da criança nas famílias de classe popular. Psicologia: Teoria e Pesquisa, 4 (3), 295-315.

Bonin, L.F.R. (1987). Representações sociais das mães a respeito da criança. Psicologia Argumento, 6 (7), 79-96.

Brasil. Congresso Nacional. (1991). Lei Federal 8.069/90, de 13 de julho de 1990. Dispõe sobre o Estatuto da Criança e do Adolescentee da outras providências. Brasília: Congresso Nacional.

Brayner, F. (2001). Da criança-cidadã ao fim da infância. Educação \& Sociedade, 22 (76), 197-211.

Calatayud, F.J.M. (1991). La promoción de salud como problema de la psicologia en la atención primaria. Revista Cubana de Medicina General, 7 (4), 362-370. 
Castro, L.R. (1996). O Lugar da infância na modernidade. Psicologia: Reflexão e Crítica, 9 (2), 307-335.

Chaves, A.M., Cabral, A., Ramos, A.E., Lordelo, L., \& Mascarenhas, R. (2002). Representação social de mães acerca da família. Revista Brasileira de Crescimento e Desenvolvimento Humano, 12 (1), 1-8.

Costa, F O., \& Antoniazzi, A.S. (1999). A influência da socialização primária na construção da identidade de gênero: percepção dos pais. Paidéia, 9 (16), 67-75.

Costa, J.F. (1983). Ordem médica e norma familiar. Rio de Janeiro: Graal.

Figueiras, A.C.M., Puccini, R.F., Silva, E.M.K., \& Pedromônico, M.R.M. (2003). Avaliação das práticas e conhecimentos de profissionais da atenção primária à saúde sobre vigilância do desenvolvimento infantil. Cadernos de Saúde Pública, 19 (6), 1691-1699.

Frank, E., \& Rowe, D. (1986). Clinical interventions in parent-infant groups around issues related to separation-individuation. Infant Mental Health Journal, 7 (3), 216-224.

Glascoe, F.P. (1997). Parents' concerns about children's development: prescreening technique or screening test? Pediatrics, 99 (4), 522-528.

Glascoe, F.P. (2000). Evidence-based approach to developmental and behavioural surveillance using parents' concerns. Child:Care, Health and Development, 26 (2), 137-149.

Glascoe, F.P., \& Dworkin, P.H. (1995). The role of parents in the detection of developmental and behavioural problems. Pediatrics, 95 (6), 829-836.

Glascoe, F.P., MacLean, W.E., \& Stone, W.L. (1991). The importance of parents' concerns about their child's behavior. Clinical Pediatrics, 30 (1), 8-11; discussion 12-4.

Graminha, S.S.V., \& Martins, M.A.O. (1994). Procura de atendimento psicológico para crianças: características da problemática relatada pelos pais. Psico PUC-RS, 25 (2), 53-79.

Guzell, J., \& Vernon-Jeagans, L. (2004). Parental perceived control over caregiving and its relationship to parent-infant interaction. Child Development, 75 (13), 134.

Lajolo, M. (1999). Infância de papel e tinta. In M.C. Freitas (Org.) História social da infância no Brasil (2. ed., pp. 229-250). São Paulo: Cortez Editora.

Lewis, C., \& Dessen, M. A. (1999). O pai no contexto familiar. Psicologia:Teoria e Pesquisa, 15 (1), 9-16.

Lo Bianco, A.C. (1981). Concepções de família em atendimentos psicológicos fora do consultório: um estudo de caso. In G. Velho \& S. Figueira (Orgs.). Família, psicologia e sociedade (pp. 151-182). São Paulo: Campus.
Lordelo, E.R., Fonseca, A.L., \& Araújo, M.L.V.B. (2000). Responsividade do ambiente de desenvolvimento: crenças e práticas como sistema cultural de criação de filhos. Psicologia: Reflexão e Crítica, 13 (1), 73-80.

Mondardo, A.H., \&Valentina, D.D. (1998). Psicoterapia infantil: ilustrando a importância do vínculo materno para o desenvolvimento da criança. Psicologia: Reflexão e Crítica, $11(3), 621-630$.

Moura, C.B., \& Gabassi, S.E. (1998). Dependência X Autonomia infantil: o papel da psicoterapia no desenvolvimento sócio-emocional de crianças imaturas. Estudos de Psicologia, 15 (3), $71-77$.

Oliveira, D.C., \& Alvarenga, A.T. (1993). Representações da realidade: discurso do senso comum e discurso técnico profissional. Revista Brasileira de Crescimento e Desenvolvimento Humano, 3 (2), 56-68.

Oliveira, D.C., Siqueira, A.A.F., \& Alvarenga, A.T. (2000). Práticas sociais em saúde: uma releitura à luz da teoria das representações sociais. In A.S.P. Moreira \& D.C. Oliveira (Orgs.). Estudos interdisciplinares derepresentação social (pp.163-190). Goiânia: AB Editora.

Oliveira, M.L.S., \& Bastos, A.C.S. (2000). Práticas de atenção à saúde no contexto familiar: um estudo comparativo de casos. Psicologia: Reflexão e Crítica, 13 (1), 97-107.

Reppold, C.T., Pacheco, J., Bardagi, M., \& Hutz, C.S. (2002). Prevenção de problemas de comportamento e desenvolvimento de competências psicossociais em crianças e adolescentes: uma análise das práticas educativas e dos estilos parentais. In C.S. Hutz (Org.). Situações de risco e vulnerabilidade na infância e na adolescência: aspectos teóricos eestratégias de intervenção (pp. 9-39). São Paulo: Casa do Psicólogo.

Resende, A.L.M., \& Alonso, I.L.K. (1995). O perfil do pai cuidador. Revista Brasileira de Crescimento e Desenvolvimento Humano, 5 (1/2), 66-81.

Rothbaum, F., Pott, M., Azuma, H., Miyake, K., \& Weisz, J. (2000). The development of close relationships in Japan and the United States: pathes of symbiotic harmony and generative tension. Child Development, 71(5), 1121-1142.

Santos, B.R. (1996). A Emergência da concepção moderna de infância e adolescência. Mapeamento, documentação e reflexão sobre as principais teorias. Dissertação de mestrado em Ciências Sociais não-publicada, Pontifícia Universidade Católica de São Paulo.

Tomás, C.A. (2001). A transformação da infância e da educação: algumas reflexões sócio-históricas. Paidéia, FFCLRP-USP, 11 (20), 69-72.

Trindade, Z.A., Andrade, C.A., \& Souza, J.Q. (1997). Papéis parentais e representações da paternidade: a perspectiva do pai. Psico, 28 (1), 207-222.

Recebido para publicação em 23 de março de 2004 e aceito em 11 de maio de 2005. 
